\title{
The response of a restrained copepod to tactile stimulation
}

\author{
C. W. Gill* \\ Marine Science Laboratories, Menai Bridge, Gwynedd LL59 5EH, United Kingdom
}

\begin{abstract}
The copepod cuticle is covered with sensory and non-sensory structures such as setae, spines and pores. Restrained individuals of the calanoid Temora longicornis Müller were stimulated with a fine hair. The only area to respond to stimulation was that of the antennules. Repeated tactile stimulation of the antennulary setae showed that the setae at the tip of the antennule were very sensitive to touch, but thereafter setae from the middle and base became progressively less sensitive. No habituation occurred. T. longicornis swims continuously, and in normal swimming the antennules are held at right angles to the body. It is reasonable for the tips to be the most sensitive part of the antennule as they can detect stimuli with least interference from the movement of other limbs.
\end{abstract}

\section{INTRODUCTION}

Various sensory and non-sensory structures such as setae, spines and pores occur on the cuticle of copepods (e.g. Fleminger, 1973; Malt, 1983). The pores are distributed in the integument in patterns that form signatures characteristic of many species and of all genera and families (Bradford, 1974; Fleminger and Hülsemann, 1977; Mauchline, 1977; Mauchline and Nemoto, 1977). Copepod receptors are too small to be studied by electrophysiology, and investigation of their function is still at a preliminary stage. To date, fine structure studies suggest that copepods probably have mechanoreceptors on their antennules (Strickler and Bal, 1973; Friedman, 1980; Gill, 1983) and chemoreceptors on their mouthparts (Ong, 1969; Friedman and Strickler, 1975; Friedman, 1977).

Earlier work (Gill and Crisp, unpubl.) showed that all parts of the copepod body were very sensitive to direct stimulation by water jets. Since amputation of the antennule or antennules greatly reduced the sensitivity of Temora longicornis to jets, the antennulary setae are the most likely receptors to be implicated in the detection of fluid disturbances. Bilateral antennular amputation did not entirely prevent the copepod from responding, which suggests there may be

\footnotetext{
- Present address: Centre d'Etudes d'Océanographie et de Biologie Marine, C.N.R.S., Station Biologique; F-29211 Roscoff, France
}

mechanoreceptors present on other areas of the body. The experiments described below were carried out to investigate if $T$. longicornis responds to touch. Various parts of the copepod body were stimulated with a fine hair, including the suspected mechanosensory setae on the antennules. The results were analysed in terms of the behavioural response of the copepod.

\section{METHODS}

Copepods were collected from the Menai Strait, Gwynedd in a medium mesh plankton net. Temora longicornis, of which only females were available, were isolated and maintained in 31 glass jars of finefiltered, u-v irradiated seawater. The copepods were fed a mixture of flagellates and diatoms, and acclimated at $10^{\circ} \mathrm{C}$ for 2 to $3 \mathrm{~d}$ before being used.

The observations described were obtained from copepods restrained in the centre of a flow chamber. The restraint device consisted of fine bore plastic catheter tubing drawn out to a very fine tip at one end, and the other end of the tube was fitted to a disposable syringe. The tip of the tube was applied to the domed cephalothorax of a copepod and suction helds the copepod against it. The suction tube was held in position by a micromanipulator. Copepods were attached horizontally, facing into a seawater flow of $0.17 \mathrm{~cm} \mathrm{~s}^{-1}$, maintained at $10^{\circ} \mathrm{C}$ and supplied by a circulating seawater system. Each copepod was kept attached to the 
suction tube without stimulation for a minimum of 45 min before each experiment.

The stimulus was applied by means of a fine human hair which was rigidly mounted in a thin plastic tube attached to a micromanipulator. The hair was fine enough to touch specific areas, even individual setae of the antennule, without interfering with other parts of the copepod.

Tactile stimulation of the various body regions. The copepod was attached slightly forward of the midpoint of the carapace. The fine hair was manipulated towards, and brushed against the surface of the following areas: the caudal rami, $\mathrm{Cr}_{\text {; }}$ urosome, $\mathrm{U}$; metasome, $M_{i}$ cephalosome, $C$; and antennules, A. Fig. 1 is a

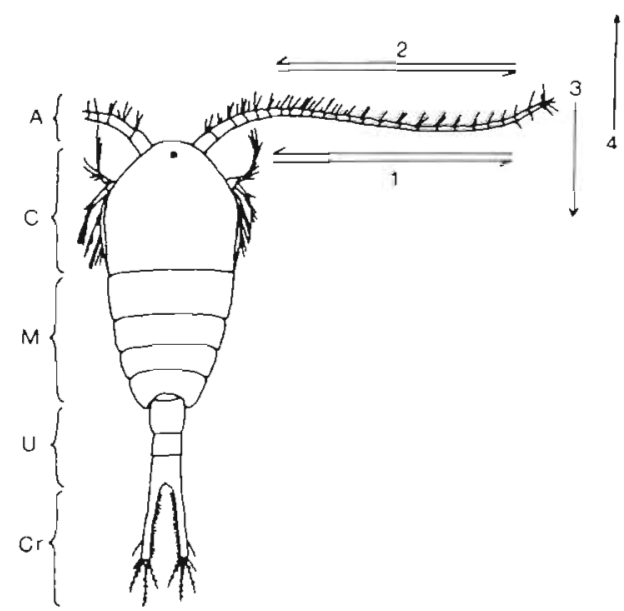

Fig. 1. Temora longicornis. Diagram of different areas and manner in which the antennule was stimulated by a fine hair

diagram of $T$. longicornis illustrating the above mentioned areas. The hair was moved across the carapace surface in several directions to ascertain whether the response had any directionality.

Temora longicornis has a row of setae on the anterior edge of the antennule, and these setae point in an anterior direction. The antennules were stimulated in the following ways (Fig. 1): The hair was (1) slowly moved against the posterior edge of the antennule, and thence towards the base or tip; (2) moved against the anterior edge of the antennule, and thence towards the base or tip; (3) slowly moved to the anterior edge of the antennule, and then used to push the antennule backwards; (4) moved to the posterior edge of the antennule and then used to push the antennule forwards.

The behaviour of the copepod immediately after the stimulus was noted. Temora longicornis commonly responds to a disturbance with an 'escape response' where the antennules are rapidly flicked back alongside the body, the legs are kicked backwards, and the urosome (tail) is flicked upwards. Alternatively, the antennules or tail may be flicked alone.
Repeated tactile stimulation of the antennulary setae. The antennules are long and narrow, consisting of 24 segments in the female. Two, or sometimes 3 setae arise proximal to the junction of each segment, and occasionally at the midpoint of a segment. The 2 setae point in an anterior direction, and subtend an acute angle with each other. All the setae are of the same size, except those at the tip of the antennule.

Setae from the left antennule of each copepod were stimulated 100 times at each of the 3 positions: base, Segments 1 to 3 ; middle, Segments 9 to 14 ; and tip, Segments 21 to 24 . The hair was positioned at the basal side of the 2 setae to be stimulated, and the hair was used to displace the setae laterally in the direction of the antennule tip. Adjacent setae and the antennule itself were not touched by the hair. The following changes in behaviour were recorded: (a) flicking the antennule once; (b) flicking the antennule repeatedly; (c) single escape response. The order of stimulation at the middle, base or tip of the antennule was changed for each copepod. There was an interval of at least 30 min between stimulation of setae from different areas. Twenty copepods were examined.

\section{RESULTS}

Tactile stimulation of the various body regions

No degree of stimulation to any part of the copepod, with the exception of the antennules (Table 1), caused a change in behaviour. Moving the hair along the fine setae on the inner edge of the caudal rami and even bending the urosome through $180^{\circ}$ did not alter the copepod's behaviour. The copepod's response to tactile stimulation of the anterior edge of the antennule (Fig. 1 , 2) was so rapid, that it was not possible to move the hair laterally for any appreciable distance. The weaker response to stimulation of the posterior edge of the antennule (Fig. 1, 1) was only obtained after the hair had been moved laterally for approximately half the length of the antennule. When the copepods flicked a

Table 1. Temora longicomis. Responses obtained from tactile stimulation of antennules

\begin{tabular}{|ll|}
\hline $\begin{array}{c}\text { Method of } \\
\text { antennule stimulation }\end{array}$ & \multicolumn{1}{c|}{$\begin{array}{c}\text { Response to antennule } \\
\text { stimulation }\end{array}$} \\
\hline Posterior (Fig. 1, 1) & $\begin{array}{l}\text { No response, or single flick of } \\
\text { antennule } \\
\text { Repeated flicks of both anten- } \\
\text { nules and escape response } \\
\text { Repeated flicks of that antennule } \\
\text { Backwards (Fig. 1, 3) 1, 2) }\end{array}$ \\
Forwards (Fig. 1, 4) & $\begin{array}{l}\text { Single flick of that antennule } \\
\text { Righe response }\end{array}$ \\
\hline
\end{tabular}


single antennule only, it was always the one which had been touched by the hair. It was possible to move the antennule a greater distance in a forward (Fig. 1,4) compared to a backward (Fig. 1,3) direction, before the copepod responded.

\section{Repeated tactile stimulation of the antennulary setae}

Means of the various changes in behaviour are given in Table 2. Percentages form a binomial rather than a normal distribution (Zar, 1974). To allow the valid application of parametric analysis of variance each

Table 2. Temora longicornis. Transformed percentages of different responses to repeated tactile stimulation of antennulary setae. (a), (b) and (c) explained in text

\begin{tabular}{|lrrrrr|}
\hline $\begin{array}{l}\text { Antennule } \\
\text { part }\end{array}$ & \multicolumn{4}{c}{$\begin{array}{c}\text { Transformed mean percentages of } \\
\text { responses } \pm \text { standard error }\end{array}$} \\
& (a) & (b) & (c) & \multicolumn{1}{c|}{ Total } \\
\hline Base & $30.10 \pm 3.6$ & $5.40 \pm 1.7$ & $2.95 \pm 0.7$ & $38.45 \pm 4.3$ \\
Middle & $49.30 \pm 9.1$ & $16.90 \pm 11.9$ & $6.05 \pm 5.2$ & $72.25 \pm 11.4$ \\
Tip & $52.25 \pm 5.5$ & $39.35 \pm 5.5$ & $5.35 \pm 1.1$ & $96.95 \pm 0.7$ \\
\hline
\end{tabular}

percentage was transformed to its arcsine. The numbers of the various responses elicited from stimulation of the base, middle and tip of the antennule were very highly significantly different $(\mathrm{P}<0.001)$. Setae at the tip of the antennule were the most sensitive, and setae from the middle and base were progressively less sensitive. There was no obvious progression in the number of responses along any small length of the antennule. However, the setae on Segment 24, which is the very tip of the antennule, were the most sensitive, responding to $99.6 \%$ of stimulations.

The most common response was a single flick of the antennule (a). After 1 to 20 stimulations of the antennule tip, each of which resulted in the antennule being

Table 3. Temora longicornis. Transformed total percentages of responses, at $1 \mathrm{~min}$ intervals, to repeated tactile stimulation of antennulary setae

\begin{tabular}{|clll|}
\hline \multirow{2}{*}{$\begin{array}{c}\text { Time after start, } \\
1 \text { min = 10 stimuli }\end{array}$} & \multicolumn{3}{c}{ Total percentage responded } \\
& Base & Middle & Tip \\
\hline $1(10)$ & 38.5 & 80.5 & 99.5 \\
2 & 28 & 72.5 & 97.5 \\
3 & 40.5 & 71 & 96 \\
4 & 39.5 & 71.5 & 98.5 \\
5 & 38.5 & 67.5 & 96 \\
6 & 36.5 & 71.5 & 97 \\
7 & 40.5 & 74.5 & 97 \\
8 & 43.5 & 71.5 & 96.5 \\
9 & 37.5 & 71.5 & 96 \\
$10(100)$ & 41.5 & 70.5 & 95.5 \\
\hline
\end{tabular}

flicked once (a), or several times (b), the copepod then gave an escape response (c). It was noted at the time that tactile stimulation of setae from the middle or tip of the antennule caused only the antennule that was stimulated to be flicked. However stimulation of setae at the base as frequently resulted in the opposite antennule being flicked.

Table 3 summarizes the percentages of responses at 1 min intervals. The total percentages of all changes in behaviour are the same, irrespective of how many times the setae had been stimulated, i.e. no habituation occurred. The percentages of the different changes in behaviour were also consistent with time.

\section{DISCUSSION}

\section{Tactile stimulation of various body regions}

In the above experiments it was first assumed that attachment of Temora longicomis to the suction tube did not alter the copepod's behaviour. This was substantiated by the lack of response to mechanical stimulation of the cephalosome.

The copepod metasome does have occasional small setae (Strickler, 1975; Blades and Youngbluth, 1979. 1980; Malt, 1983) which may have been directly stimulated by the hair. However the chances of having touched one must have been low as the maximum number noted on a body segment was 3 , and some segments have none (Gill, 1983). The thoracic segments of the metasome have dense areas of cuticular spines which are not thought to be mechanosensitive. Touching these areas with a hair did not alter the copepod's behaviour.

Touching any area of Temora longicornis, except the antennules, did not cause a change in behaviour. Yet a fine jet of water directed at these areas (Gill and Crisp, unpubl.) always caused a response. In the natural environment, the rapid reaction of the copepod would usually remove it from potential predators before actual contact was made. Therefore, it may not be so important for the copepod to respond to touch, except when particles or prey made contact with the antennules, and the latter were found to be mechanically sensitive, especially at the tip. The touch of a fine hair and a fine water jet would have much the same effect on a simple mechanoreceptor causing it to bend or otherwise deform. However water jets may affect a much larger area than a hair, and so appear to cause changes in behaviour when applied to regions thought to be unresponsive.

The greater sensitivity of the anterior in contrast to the posterior surface of the antennules was probably due to the ready stimulation of the setae, which are 
found only on the anterior surface. Temora longicornis did not respond to the touch of the hair against the posterior surface, until the antennule had been clearly displaced forwards. Movement of the antennule and consequently the setae may have caused the delayed responses. The antennules are flicked backwards during an escape response, and in the above experiments movements of the antennules in this direction caused a rapid response. Flicking of the antennules forwards is not a natural movement for $T$. longicornis, and the copepod was less sensitive to movements of the antennules in this direction.

Yule (1982) found that the posterior and anterior regions of Balanus balanoides cypris larvae were more sensitive to touch than the flanks. The cyprid carapace is covered with small sensory setae (Walker and Lee, 1976) which are more densely aggregated at the tips of the carapace than on the flanks. The only appendages of Temora longicornis sensitive to touch are also covered with sensory setae, i.e. the antennules (Gill, 1983). Park (1966) also found that the antennules of a copepod were sensitive to touch. He elicited an escape response from Epilabidocera amphitrites by touching the antennules with a fine glass needle. The copepods always moved in the opposite direction from the antennule stimulated.

\section{Repeated tactile stimulation of antennulary setae}

The setae were very sensitive to touch at the tip of the antennule but thence became progressively less sensitive. There are approximately 6 setae at the tip of segment 24 which point in several directions (Fig. 1). and therefore may be capable of responding to stimuli from any direction. In addition to the setae on the anterior edge of the antennule, the final 3 segments also have setae on the posterior edge, and these setae point in a posterior direction (Fig. 1). These setae are also sensitive to the touch of a hair, and may contribute to the greater sensitivity of the antennule tip.

The most common response of Temora longicornis to the touch of a seta was to flick the antennular tip. When setae at the base of the antennule were stimulated, the opposite antennule was flicked as frequently as the stimulated one. Fig. 1 shows how Segments 1 and 2 project in front of the copepod, and the rest of the antennule is bent at right angles to the body of the copepod. The close proximity of the setae from Segments 1 and 2 of the opposite antennule may have caused antennule to be flicked, even though the opposite setae were not touched. Furthermore, it must be borne in mind that the bending forces that were applied mechanically were far greater than those necessary for natural stimulation.
There was no waning of response with time as the copepod was as likely to respond to the 100th stimulation of a seta as it was to the first. This was as expected, for a motile copepod must continually respond to stimuli or be eaten by predators.

The majority of copepods swim intermittently, and it has been suggested that mechanoreception takes place during the sinking phase of hop and sink swimming (Haury and Weihs, 1976; Kerfoot et al., 1980). Landry (1978) suggested that the copepod Labidocera trispinosa uses the long setae located at the base of each antennule to sense disturbances generated by prey. $L$. trispinosa has a greater variety of setal types which are closer together and longer in length at the base, compared with those at the tip of the antennule (Sars, 1903). Temora longicornis appears to use the antennulary setae to sense disturbances in the surrounding water (Gill and Crisp, unpubl.). The above experiments show that the tip of the antennule is the most sensitive to touch, furthermore, that $T$. longicornis has setae of the same type and length along the antennule (Gill, 1983). However, unlike L. trispinosa, T. longicornis swims continuously, and in normal swimming the antennules are held at right angles to the body. It is reasonable for the tips to be the most sensitive part of the antennules as they are further away from the body and so can detect stimuli with least interference from the movement of other limbs.

Acknowledgements. I thank Professor D. J. Crisp, C.B.E., F.R.S., for providing facilities for this research project, and constructively criticising the original manuscript. I am also grateful to R. P. Harris for useful comments. This work was supported by a grant from the Natural Environment Research Council.

\section{LITERATURE CITED}

Blades, P. I., Youngbluth, M. J. (1979). Mating behaviour of Labidocera aestiva (Copepoda: Calanoida). Mar. Biol. 51: 339-356.

Blades, P. I., Youngbluth, M. J. (1980). Morphological, physiological and behavioural aspects of mating in calanoid copepods. In: Kerfoot, W. C. (ed.) Evolution and ecology of zooplankton communities. University Press of New England, New Hampshire, p. 39-51

Bradford, J. M. (1974). New and little known Arietellidae (Copepoda: Calanoida) mainly from the southwest Pacific N. Z. Jl mar. Freshwat. Res. 8: 523-533

Fleminger, A. (1973). Pattern, number, variability and taxonomic significance of integumental organs in Eucalanus (Copepoda: Calanoida). Fish. Bull. U.S. 71; 965-1010

Fleminger, A., Hülsemann, K. (1977). Geographical range and taxonomic divergence in north Atlantic Calanus ( $C$. helgolandicus, C. finmarchicus and C. glacilis). Mar. Biol. 40: 233-248.

Friedman, M. M. (1977). Electron microscopic studies of the filter-feeding mechanism of calanoid copepods. Ph. D. thesis, John Hopkins University, Baltimore, Maryland 
Friedman, M. M. (1980). Comparative morphology and functional significance of copepod receptors and oral structures. In: Kerfoot, W C. (ed.) Evolution and ecology of zooplankton communities. University Press of New England, New Hampshire, p. 185-197

Friedman, M. M., Strickler, J. R. (1975). Chemoreceptors and feeding in calanoid copepods. Proc. natn. Acad. Sci. U.S. A. $72: 4185-4188$

Gill, C. W. (1983). The swimming responses of planktonic organisms, particularly Temora longicornis Müller. Ph. D. thesis, University College of North Wales, Bangor

Haury, L. R., Weihs, D. (1976). Energetically efficient swimming behaviour of negatively buoyant zooplankton. Limnol. Oceanogr. 21: 797-803

Kerfoot, W. C., Kellogg, D. L., Jr., Strickler, J. R. (1980). Visual observations of live zooplankters: evasion, escape and chemical defences. In: Kerfoot, W. C. (ed.) Evolution and ecology of zooplankton communities. University Press of New England, New Hampshire, p. 10-27

Landry, M. R. (1978). Predatory feeding behaviour of a marine copepod, Labidocera trispinosa. Limnol. Oceanogr. 23: 1103-1113

Malt, S. J. (1983). Polymorphism and pore signature patterns in the copepod genus Oncaea (Cyclopoida). J. mar. biol. Ass. U. K. 63: 449-466

Mauchline, J. (1977). The integumental sensilla and glands of pelagic crustacea. J. mar. biol. Ass. U. K. 57: 973-994
Mauchline, J., Nemoto, T. (1977). The occurrence of integumental organs in copepodid stages of calanoid copepods. Bull. plank. Soc. Jap. 24: 32-38

Ong, J. E. (1969). The fine structure of the mandibular sensory receptors in the brackish water calanoid copepod Gladioferens pectinatus. Z. Zellforsch. 97: 178-195

Park, T. S. (1966). The biology of a calanoid copepod, Epilabidocera amphitrites. Cellule 66: 129-251

Sars, G. O. (1903). An account of the crustacea of Norway. IV. Copepoda: Calanoida. Bergen Museum, Bergen

Strickler, J. R. (1975). Swimming of planktonic Cyclops species (Copepoda: Crustacea): pattern, movements and their control. In: Wu, Y.-T., Brokaw, C. J., Brennen, C. (ed.) Swimming and flying in nature, Vol. 2. Plenum Press, New York, p. 599-613

Strickler, J. R., Bal, A. K. (1973). Setae of the 1st antennae of the copepod Cyclops scutifer: their structure and importance. Proc. natn. Acad. Sci. U.S. A. 70: 2656-2659

Walker, G., Lee, V. E. (1976). Surface structures and sense organs of the cypris larva of Balanus balanoides as seen by scanning and transmission electron microscopy. Microscopy J. Zool. Lond. 178: 161-172

Yule, A. B. (1982). The application of new techniques to the study of planktonic organisms. Ph. D. thesis, University College of North Wales, Bangor

Zar, J. H. (1974). Biostatistical analysis. Prentice-Hall Inc., Englewood Cliffs, N. J.

This paper was submitted to the editor; it was accepted for printing on October 2, 1984 